\title{
AVALIAÇÃO DE PROJETOS SOCIAIS COMO OPORTUNIDADE DE PARTICIPAÇÃO E QUALIFICAÇÃO DAS AÇÕES
}

\author{
Mariani Signori, Dunia Comerlatto \\ Mestrado em Políticas Sociais e Dinâmicas Regionais da Universidade Comunitária da \\ Região de Chapecó (UNOCHAPECÓ), Chapecó - SC
}

\begin{abstract}
Resumo
O presente artigo discorre sobre a organização do sistema de monitoramento e avaliação dos projetos sociais desenvolvidos na Universidade Comunitária da Região de Chapecó, como trabalho final do Mestrado Profissional em Políticas Sociais e Dinâmicas Regionais. O monitoramento e a avaliação de projetos sociais são oportunos como mecanismos para ampliar a participação e a qualificação dos processos de gestão que se coloca compartilhado entre o Estado e organizações da sociedade civil. Os processos avaliativos de projetos sociais se configuram numa "prática política". Na busca de organizar um sistema de monitoramento e avaliação dos projetos sociais, trilhou-se o trabalho de intervenção no segundo semestre de 2011. Utilizou-se como estratégia metodológica a pesquisa-ação, pautando a abordagem participativa no processo investigativo e propositivo para construção desse sistema. Avaliar de modo participativo não é tarefa fácil. Exige participação ampla e efetiva dos envolvidos nos processos constitutivos de monitoramento e avaliação de ações sociais.
\end{abstract}

Palavras-chaves: Gestão Social. Projetos sociais. Avaliação participativa.

\begin{abstract}
This article discourse the monitoring's system organization and evaluation of social projects developed at Chapecó Region Community University (Unochapecó) as the last work of the Master's Degree in Social Policy and Regional Dynamics. The monitoring and the evaluation of social projects are timely as mechanisms to increase participation and qualification of management processes that are shared between the State and civil society organizations. The evaluation processes of these projects are configured at "practical politics". In seeking to organize a system of monitoring and rate the social projects, an intervention work happened in the second half of 2011. It was used as a methodological strategy to action-research, guiding the participatory approach in the investigative process and proposals for construction of this system. Evaluating in a participatory way is no easy task. Requires broad and effective participation of those involved in the constitutive process of monitoring and evaluation of social actions.
\end{abstract}

Keywords: Social management. Social projects. Participatory evaluation

Recebido 22/11/2012; Aceito 22/12/2012

RBPD - Revista Brasileira de Planejamento e Desenvolvimento, v. 1 , n. 1, p. 40-51 , jul./dez. 2012 


\section{Introdução}

Na lógica do processo de mundialização do capital, globalização econômica e reforma do Estado, o governo brasileiro compartilha com a sociedade civil e a iniciativa privada funções consideradas não exclusivas. Ou seja, funções relacionadas com atividades essenciais à população, mas que não se configuram como exclusivas do Estado, principalmente no que se refere à área social. Com isso, o Brasil passa por transformações na gestão das políticas públicas, abrindo possibilidade para a participação da sociedade civil organizada.

A Constituição Federal de 1988 se apresenta como um marco que legitima a articulação entre Estado e sociedade e o direito de partilhar o planejamento, implementação e avaliação das políticas, ampliando o controle social dessas ações por meio da participação na gestão pública.

O monitoramento e a avaliação de projetos sociais no contexto da moderna gestão social tornam-se oportunos como mecanismos para ampliar a participação, a organização de um sistema avaliativo e, em decorrência, a qualificação dos processos, considerando que a gestão das ações sociais em âmbito brasileiro, coloca-se, em seu modus operandis, compartilhada entre o Estado, organizações da sociedade civil e de iniciativa privada.

Várias são as organizações não estatais que podem assumir serviços sociais e científicos, aonde os investimentos na infra-estrutura e nos serviços públicos não são, a rigor, uma atividade exclusiva do Estado, na medida em que podem ser objeto de concessão. De escolas, universidades, centros de pesquisa científica e tecnológica, creches, ambulatórios, hospitais, entidades de assistência aos carentes - menores e velhos, museus, orquestras sinfônicas, oficinas de arte, emissoras de rádio e televisão educativa, etc... ${ }^{1}$.

No caso das universidades, destacadamente àquelas de caráter público, denominadas Universidades Comunitárias com trajetória de inserção nas comunidades, executam inúmeros projetos sociais assumidos institucionalmente pela área da extensão universitária em estreita relação com as áreas do ensino e da pesquisa. Vinculado a essas universidades, suas fundações ou associações mantenedoras gozam do direito de se instituírem como Entidades Beneficentes de Assistência Social (EBAS), podendo assim, investir recursos financeiros na concessão de bolsas de estudos e/ou na execução de projetos sociais.

Esse potencial de investimentos torna possível a oferta de ações públicas destinadas a diferentes públicos-alvo: criança e adolescente, mulheres, idosos. Nessa direção, a oferta de ações deve se pautar em orientações e procedimentos fundamentais ao Estado Democrático de Direitos na direção de consolidar o controle social e a qualidade operacional das ações desenvolvidas.

Esse contexto imprime a necessidade de novas estratégias e acordos entre as diferentes esferas de governo e sociedade civil organizada, no que se refere: à definição de prioridades de atendimentos das demandas sociais; às formas de atendimentos; às responsabilidades; às metas e aos objetivos; e aos critérios de avaliação e gestão de recursos. Esses procedimentos de gestão definem as políticas e suas formas de implementação, ao se utilizarem de mecanismos para o seu planejamento, execução e avaliação.

A materialização das políticas públicas no atendimento às demandas sociais se traduz em processos de intervenção social e articulação dos diferentes atores, por meio de programas

\footnotetext{
${ }^{1}$ Ver Cadernos MARE da Reforma do Estado - no 1 - Brasília/DF, 1997.
} 
e projetos. Armani (2009, p. 18) conceitua o projeto como "uma ação social planejada estruturada em objetivos, resultados e atividades baseados em quantidade limitada de recursos (humanos, materiais e financeiros) e de tempo". Já Stephanou (2003, p. 25), acrescenta a essa conceituação o argumento de que os projetos são ferramentas de trabalho como forma de "organizar ações para transformar uma determinada realidade social ou institucional", ou seja, instrumentos capazes de articular e qualificar ações para alcance de resultados transformadores.

Nessa perspectiva, um projeto social tem seu horizonte na busca da melhoria da qualidade de vida dos grupos sociais envolvidos. Portanto, é de fundamental importância que ao serem planejados, levem em conta as demandas que se apresentam em meio à realidade a ser trabalhada. Sobre isso, Stephanou (2003, p.15) reforça que "os projetos são ações estruturadas e intencionais de um grupo ou organização social, que partem da reflexão e do diagnóstico sobre uma determinada problemática e buscam contribuir, em alguma medida para um outro mundo possível”.

Ao considerar as problemáticas às quais os projetos sociais se direcionam, estabelecem-se permanentes negociações e parcerias diante das possibilidades institucionais em empreender recursos humanos e financeiros a fim de dar cobertura e alcançar resolutividade às questões que necessitam ser enfrentadas. Embora existam limitações na implantação, execução e avaliação de projetos sociais, especialmente no que tange as questões financeiras, temporais e de gestão, os projetos sociais se constituem numa atuação estratégica para promover ações de cunho socioassistencial.

Mesmo reconhecendo algumas limitações, "os projetos ainda são, e tudo indica que continuarão a sê-lo por um bom tempo, a forma mais adequada para promover a viabilidade e o êxito de ações sociais transformadoras" (ARMANI, 2009, p. 21). Para tanto, os projetos sociais precisam estabelecer gradativamente a credibilidade em meio aos diferentes públicos envolvidos, quer sejam os financiadores, a equipe de trabalho ou a população usuária.

O monitoramento e avaliação podem ser considerados como uma das formas de promover essa credibilidade para com o público-alvo envolvido, uma vez que traduz a transparência dos processos, a possibilidade de redimensionamento das ações e a análise do grau de atendimento dos objetivos propostos.

A experiência profissional na Universidade Comunitária da região de Chapecó (Unochapeco), junto à equipe técnica da Diretoria de Extensão como assistente social, vinculada à execução de projetos sociais ao longo de dez anos, posicionou a necessidade de organizar um sistema de monitoramento e avaliação dos projetos sociais nela desenvolvidos. Associada a essa experiência, a vinculação com o Mestrado Profissional de Políticas Sociais e Dinâmicas Regionais ${ }^{2}$ permitiu desenvolver um trabalho final seguindo essa finalidade.

Como parte do trabalho final de conclusão desse curso ${ }^{3}$, este artigo descreve sobre aspectos centrais que permeiam a organização de um sistema de monitoramento e avaliação como mecanismo de gestão social participativa ao processo de construção que pautou tal organização e a organização do sistema avaliativo de projetos sociais em seus processos metodológicos e resultados alcançados.

\footnotetext{
${ }^{3}$ Consultar Art. 70 inciso III, § 3 da PORTARIA NORMATIVA No 17, DE 28 DE DEZEMBRO DE 2009, que dispõe sobre o mestrado profissional no âmbito da Fundação Coordenação de Aperfeiçoamento de Pessoal de Nível Superior - CAPES.
} 


\section{Avaliação participativa como mecanismos de gestão social}

Compartilhar responsabilidades com o Estado na gestão de ações desencadeia processos decisórios em que a sociedade civil organizada, por intermédio de diferentes atores e organizações, coloca-se protagonista na definição da agenda pública governamental. Instaura-se assim um novo modelo de gestão social participativa, aonde a sociedade contribui na definição das prioridades da agenda pública e no exercício do controle social. Com isso, configura-se um novo modelo de relação Estado Sociedade, em meio à gestão participativa e à articulação da sociedade civil com o Estado, ao permitir

Que a Sociedade Civil compartilhe não apenas a execução, mas, sobretudo, os espaços de tomada de decisão, atuando no planejamento, monitoramento e avaliação destas políticas. O desafio das políticas públicas é assegurar uma relação de participação e boa articulação entre os setores sociais envolvidos nas instâncias da gestão compartilhada. (STEPHANOU, 2003, p. 11).

Nessa configuração da gestão das políticas públicas, o Estado passa a ser agente de regulação e financiamento desempenhando o papel de articulador e fortalecedor de organizações parceiras, uma vez que a gestão da política social está embasada na parceria entre Estado, sociedade civil e iniciativa privada (CARVALHO, 2001).

Assim, o coletivo de atores e organizações pode elevar os patamares de participação e controle social na definição, planejamento, implementação e avaliação das políticas públicas, redefinindo as fronteiras entre o público e o privado, ao considerar que

O Estado deixou de ser o único executor de políticas sociais e começou a priorizar seu papel de articulador e regulador dessas políticas. Com isso cresce a participação de outros atores, tais como a iniciativa privada, as organizações não-governamentais, organismos internacionais, movimentos sociais e outros grupos organizados. (STEPHANOU, 2003, p. 15).

As avaliações podem ser realizadas de diferentes formas e por diferentes agentes. Podem ser realizadas por pessoas da própria instituição proponente do projeto a ser avaliado, denominada de avaliação interna. Podem ser realizadas por pessoas de outras instituições, contratadas para esse fim, denominada de avaliação externa. Podem ser realizadas de forma mista, por pessoas da instituição proponente juntamente com pessoas de outras instituições. E, ainda, avaliação com abordagem participativa, aonde envolve as equipes de trabalho e a comunidade atendida.

Sobre isso, Cohen e Franco (2002) elucidam que é possível diferenciar quatro tipos de avaliação, conforme a característica dos agentes avaliadores, que são: (a) avaliação interna, realizada dentro da própria instituição gestora ou proponente do projeto, considerada interessante uma vez que os agentes avaliadores conhecem bem a realidade a ser avaliada; (b) avaliação externa, realizada por pessoas que não estão diretamente vinculadas a instituição proponente do projeto, geralmente são especialistas contratados para esse fim, podendo haver o inconveniente dos avaliadores não dominarem a realidade a ser avaliada; (c) avaliação mista, pretende combinar a avaliação interna com a externa, minimizando as dificuldades e preservando as vantagens de cada uma; (d) avaliação participativa, aproxima os avaliadores e os beneficiados, requisitando a participação da comunidade em todos os processos de um 
projeto, desde o planejamento, execução e avaliação, a qual normalmente é utilizada em projetos de esfera mais local.

No caso da avaliação participativa, essa tem como característica principal a participação dos gestores, implementadores e beneficiários de um projeto social, possibilitando aos agentes envolvidos não somente a apropriação da realidade como também a construção de novas propostas e ações de intervenção. Apropria-se de procedimentos metodológicos muitas vezes utilizados na pesquisa-ação, por ser uma avaliação de abordagem participativa em seu processo investigativo e propositivo. Nessa perspectiva, a avaliação participativa

Ganha destaque pelo seu uso frequente na avaliação institucional e na avaliação de programas e projetos sociais. Surgiu na esteira da chamada pesquisa ação. Guarda assim propósitos, princípios, procedimentos e estratégias muito próximos dos utilizados nesse tipo de pesquisa. (CARVALHO, 2001, p. 82).

Ao considerar que a avaliação participativa potencializa a utilização de técnicas inerentes à pesquisa-ação, garantindo a participação dos envolvidos e trazendo maior densidade aos processos ao oportunizar melhorias nas ações, o uso de instrumentos de coletas de dados tais como: questionários, entrevistas, reuniões, grupos focais, oficinas, observações e outros se tornam fundamentais e imprescindíveis (CARVALHO, 2001). Isso porque a avaliação de projetos tem se tornado cada vez mais necessária, em meio ao cenário moderno de gestão das políticas sociais em que são compartilhadas as responsabilidades entre Estado e Sociedade Civil e, ao mesmo tempo as ações executadas são fiscalizadas na direção de qualificá-las e exercer o devido controle social.

Os processos avaliativos de projetos sociais devem se colocar intrínsecos no dia a dia das organizações, ou seja, devem se configurar numa "prática política" em que os investimentos se posicionem como meio eficaz para o alcance de resultados e de efeitos sejam afirmativos na vida das pessoas envolvidas.

A avaliação não deve ser pensada apenas como um momento do projeto, o que para Stephanou (2003, p. 85) não pode ser "aquela parada no final de ano na qual a gente senta e avalia o que fez. Devemos organizar o projeto para que as avaliações sejam contínuas, ao longo do desenvolvimento do trabalho".

Esse alerta de Stephanou remete para a necessidade de desencadear processos de monitoramento e avaliação das ações em execução. O monitoramento também é denominado de acompanhamento, é realizado no cotidiano de projeto, revisando objetivos, metodologias, ações, recursos e resultados. Trata-se de uma forma específica de avaliação e se detém em resultados imediatos, uma vez que acompanha em tempo real as ações realizadas (STEPHANOU, 2003).

Nesse sentido, "não se pode fazer o monitoramento sem um projeto que especifique de forma clara os resultados que pretende atingir e a cadeia de ações proposta para lançar esses objetivos." (CARVALHO, 2001, p. 74). Assim, o monitoramento tem o papel de acompanhar as atividades, de determinada política, programa ou projeto social, conforme previstas no planejamento, possibilitando ajustes imediatos caso haja necessidade.

Carvalho (2001, p. 74) ressalta ainda que "o monitoramento durante a implementação e execução é imprescindível, pois fornece informações importantes sobre dificuldades no desempenho do projeto que podem afetar a obtenção das metas ou resultados propostos [...]." Dessa forma, a avaliação está para cumprir "o papel de analisar criticamente o andamento do 
projeto segundo seus objetivos, tendo por base as informações produzidas pelo monitoramento" (ARMANI, 2009, p. 69).

As considerações descritas em defesa do monitoramento e avaliação como complementares entre si na gestão de programas e projetos sociais, torna imperativa a instituição de um fluxo avaliativo que se utilize um conjunto de procedimentos para acompanhamento e análise realizados ao longo da implementação de um projeto social, buscando verificar se as atividades e resultados correspondem ao que foi planejado monitoramento, e se os objetivos propostos estão sendo alcançados - avaliação (ARMANI, 2009).

Esse procedimento permite à gestão de projetos sociais, maior "controle" por parte da equipe executora, assim como dos próprios gestores e de outras instâncias como instituições e agências financiadoras, uma vez que possibilita a transparência das ações. Armani (2009) reforça que o papel principal de um fluxo avaliativo não consiste no "controle", mas sim na reflexão do aprendizado que é oportunizada à equipe executora, como condição fundamental de qualificação dos processos participativos, de decisão e alcance de resultados.

\section{A organização do sistema avaliativo de projetos sociais: processos metodológicos e resultados alcançados}

Na busca de organizar um sistema de monitoramento e avaliação dos projetos sociais desenvolvidos na Universidade Comunitária da Região de Chapecó (Unochapecó) ${ }^{4}$, trilhou-se um processo metodológico de trabalho de campo durante o segundo semestre de 2011. Balizado pelos objetivos específicos: (a) sistematizar os projetos sociais cadastrados na Diretoria de Extensão da Universidade Comunitária; (b) discutir sobre a importância da avaliação com as equipes de trabalho dos projetos sociais; (c) construir instrumentos de monitoramento e avaliação juntamente com as equipes de trabalho dos projetos sociais; (d) reconhecer os instrumentos/mecanismos de monitoramento e avaliação dos projetos sociais, atualmente utilizados pela Diretoria de Extensão; (e) organizar um fluxo do sistema de monitoramento e avaliação dos projetos sociais, os resultados alcançados podem ser observados pelas descrições registradas na sequencia.

A equipe de trabalho dos projetos sociais nessa Universidade soma um número significativo de profissionais (professores e técnicos administrativos) e estagiários bolsistas. Por essa razão, optou-se por utilizar como estratégia metodológica a pesquisa-ação, compreendendo-a como estratégica para pautar a abordagem participativa no processo investigativo e propositivo implicados na construção do sistema de monitoramento e avaliação dos projetos socais.

Essa estratégia metodológica para Thiollent (2007, p. 16) "é um tipo de pesquisa social com base empírica que é concebida e realizada em estreita associação com uma ação ou com a resolução de um problema coletivo". Um dos objetivos da pesquisa-ação é a

\footnotetext{
${ }^{4}$ Por se caracterizar como Projeto de Intervenção, foi submetido, ao Conselho Universitário/Comitê de Extensão da Unochapecó, no dia 11 de setembro de 2011, conforme Convocação N.008/C.EXT./2011, para fins de conhecimento e registro.
} 
transformação da realidade estudada, muito além do conhecimento adquirido por meio da pesquisa. Quando se trata da pesquisa-ação participativa, esse conhecimento retorna para a comunidade estudada pelas resoluções de problemas.

Para organizar o referido sistema avaliativo na Unochapecó, alguns procedimentos se fizeram necessários para subsidiar o trabalho de campo em termos da coleta e sistematização dos dados. Esses procedimentos se constituíram em: (a) sistematização dos projetos sociais em andamento; (b) discussão coletiva sobre a importância do monitoramento e avaliação de projetos sociais; (c) construção coletiva de um formulário avaliativo; (d) construção coletiva de um texto explicativo contendo a definição dos termos para apoiar o preenchimento desse formulário; (e) construção, juntamente com a equipe de trabalho da Diretoria de Extensão de um roteiro de visitas aos projetos sociais; (f) revisão do roteiro utilizado por essa Diretoria para guiar o preenchimento de relatórios parciais e finais; (g) definição do fluxo avaliativo, contendo os passos a serem seguidos com vistas a firmar o sistema de monitoramento e avaliação dos projetos sociais.

$\mathrm{Na}$ busca de dialogar, com as equipes envolvidas na operacionalização dos projetos sociais, focalizaram-se algumas questões: (a) o entendimento referente monitoramento e avaliação; (b) a importância atribuída à organização de um sistema de monitoramento e avaliação no âmbito dos projetos sociais; (c) os critérios a serem estabelecidos para pautar um sistema de monitoramento e avaliação; (d) os parâmetros e indicadores de avaliação.

Para deflagrar o diálogo em trono dessas questões, realizou-se a edição de dois grupos focais, envolvendo as equipes de trabalho dos projetos sociais em andamento. Romero (2008, p. 88) destaca que o grupo focal "consiste em uma sessão grupal informal de pessoas que representam os sujeitos do estudo, para discutir vários tópicos ou um tópico específico". Já Minayo e Deslandes (2002, p. 209) apontam que o grupo focal se constitui numa estreita conversação em "grupos pequenos e homogêneos. E, para serem bem sucedidos, precisam ser planejados, pois visam obter informações, aprofundando a interação entre os participantes, seja para gerar consenso, seja para explicar divergências".

As equipes de trabalho envolvidas nos projetos sociais foram convidadas, para participarem dos grupos, levando ao seu conhecimento o cronograma dos dois dias estabelecidos para o trabalho grupal. Assim, algumas das pessoas convidadas para o segundo dia, optaram em participar no primeiro dia, sendo que outras não compareceram em ambos os dias marcados.

A discussão coletiva, na forma de grupo focal, com as equipes envolvidas diretamente nos projetos sociais e com os coordenadores de núcleos de extensão espaços em que esses projetos se agregam, afirmou a necessidade de implementação de um sistema de avaliação dos projetos sociais desenvolvidos pela Unochapecó. Sua importância foi reconhecida levando em conta duas questões: (a) o compromisso público pelo montante de investimento público destinado a esses projetos; (b) a promoção de qualificação dos projetos em andamento no sentido de redimensionar os processos de gestão, de relações e de alcance dos resultados.

Após ter discutido sobre a importância do monitoramento e avaliação com a equipe envolvida na coordenação e execução dos projetos sociais e, ter sido evidenciada a necessidade de organizar um sistema avaliativo, realizou-se oficina para trabalhar na construção de formulário como um instrumento capaz de gerar informações aos processos de monitoramento e avaliação.

Discutiu-se sobre projetos sociais, avaliação, parâmetros e indicadores de avaliação, com base em Armani (2009). Para tal, elaborou-se uma síntese a fim de subsidiar essa discussão durante a realização da oficina de trabalho. 
Após a discussão conceitual sobre indicadores de avaliação, foram revisitados os documentos oficiais da Unochapecó, referidos pelos participantes do grupo focal, como aqueles que devem pautar o sistema avaliativo, quais sejam: (a) os princípios da Extensão Universitária Institucional; (b) a Missão e Visão Institucional; (c) a Política de Extensão Universitária; (d) o Plano de Desenvolvimento Institucional; (e) e a Política Nacional de Assistência Social.

A releitura e análise desses documentos permitiram aos participantes desse grupo a apropriação de elementos, em apoio à definição de parâmetros e dimensões, para o monitoramento e avaliação dos projetos sociais. Foi possível compreender a dificuldade de serem construídos indicadores quantitativos e qualitativos mais específicos, ao considerar a natureza diferenciada das ações executadas e as especificidades de funcionamento em meio a gama dos projetos sociais em andamento nessa Universidade Comunitária. Assim, optou-se por estabelecer parâmetros e/ou dimensões mais genéricas.

A partir de então, definiu-se sobre a possibilidade de trabalhar com parâmetros ou dimensões em uma primeira oficina, considerando dimensão como "o sentido em que se mede a extensão para avaliá-la; tamanho; importância" (FERREIRA, 2000, p. 237) e parâmetro como "uma variável que se atribui papel particular e destino de outras variáveis" (FERREIRA, 2000, p. 514). Para Armani (2009), variáveis são os elementos fundamentais de um fenômeno que quando observados ao longo tempo, "são capazes de nos dar uma boa idéia do grau de realização dos objetivos do projeto em questão" (p. 61).

Assim, os parâmetros e as dimensões avaliativas estabelecidas nessa oficina, ficaram assim constituídos: (a) identificação; (b) estrutura de recursos humanos, física e orçamentária; (c) relação com as políticas sociais e institucionais; (d) relação com o público alvo; (e) articulação e parcerias institucionais; (f) relação ensino/pesquisa/extensão; (g) relação com a comunidade. Uma vez constituídos, debateram-se sobre os itens para compor cada um desses parâmetros ou dimensões avaliativos. Ficou combinado entre os participantes, que esses itens, uma vez sistematizados, seriam debatidos entre as equipes de trabalho, cabendo para uma próxima oficina, validá-los e traduzi-los na forma de "Formulário Avaliativo".

Na segunda oficina então, esse formulário foi construído, revisto e aprovado por todos os participantes, uma vez que as sugestões foram discutidas amplamente junto às equipes envolvidas nos projetos sociais. Vinculado a esse formulário, foi sugerido pelos participantes da segunda oficina, a elaboração de um "Texto Explicativo" com a definição de termos a fim de guiar o preenchimento das informações para o formulário. Mais uma vez, os participantes dessa segunda oficina apreciaram esse documento, retornando à Diretoria de Extensão da Universidade para sua finalização.

Outro passo dado no processamento da organização do sistema de monitoramento e avaliação dos projetos sociais foi elaborar um "Roteiro de Visita" aos projetos sociais, juntamente com a equipe técnica da Diretoria de Extensão. As visitas planejadas cumprem a finalidade de acompanhar/monitorar as ações realizadas em cada um dos projetos desenvolvidos pela Universidade.

À Diretoria de Extensão da Universidade, cabe a gestão dos projetos sociais. Para tanto, tem estabelecido um "Cadastro de Projetos Sociais" contendo dados cadastrais em torno de: (a) identificação; (b) dados operacionais; (c) justificativa; (d) objetivos; (e) metodologia; (f) atividades a serem desenvolvidas; (g) equipe de trabalho; (h) orçamento; (i) cronograma. Esse cadastro, vigente há aproximadamente uma década, serviu como uma das bases documentais para efetuar a sistematização dos projetos sociais desenvolvidos pela Universidade Comunitária da Região de Chapecó. 
Ainda, a avaliação dos projetos sociais nessa Universidade vem acontecendo por meio de "Reuniões Sistemáticas" entre a Diretoria de Extensão e os coordenadores dos projetos, aonde são destacadas as dificuldades e potencialidades de cada um, dando encaminhamentos necessários para qualificação dos processos administrativo-operacionais. E, mais, os "Relatórios Semestrais e Anuais" se constituem em mais um dos instrumentos vigentes de avaliação. Esses relatórios são analisados pela equipe técnica da Diretoria de Extensão, composta por um assistente social, um analista de projeto, um auxiliar administrativo e um assistente administrativo. Uma vez analisados, são arquivados para fins meramente administrativos.

A avaliação dos projetos sociais na Unochapeco, vigente há uma década, necessitava ser revista e redimensionada na direção de agregar a lógica de sistema avaliativo que ultrapassasse atividades pontuais caracterizadas como tarefas meramente administrativas. Desse modo, os novos instrumentos e o percurso a ser trilhado para a organização de um sistema de monitoramento e avaliação dos projetos sociais, pode ser observado pela Figura 1, ao explicitar o fluxo avaliativo a ser seguido: 
$\boldsymbol{R} \boldsymbol{B} \boldsymbol{P} \boldsymbol{D} \quad$ AVAliaÇÃO de PROJETOS SOCIAIS COMO OPORTUNIDADE ...

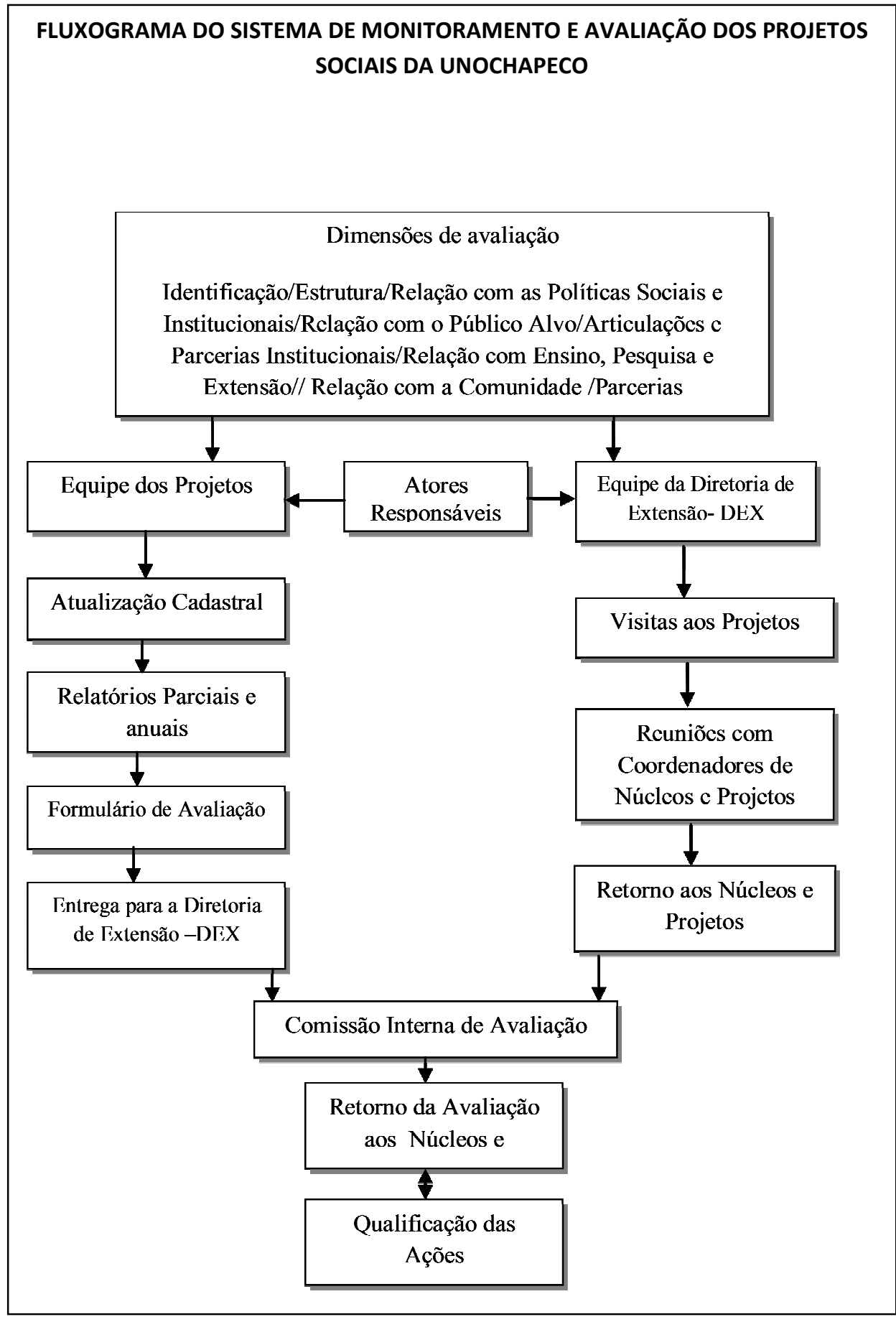

Esse fluxo, busca dar organicidade e dinamicidade ao sistema de monitoramento e avaliação dos projetos sociais proposto à essa Universidade Comunitária. 


\section{CONSIDERAÇÕES FINAIS}

No contexto brasileiro, a avaliação de programas e projetos sociais, mesmo que na história recente venha sendo apontada como imprescindível, apresenta-se ainda incipiente, parcial e descontínua como modo de operação em grande parte das organizações que executam ações sociais. Muito embora, os projetos financiados com recursos públicos venham exigindo análise sobre os investimentos aplicados, as avaliações acontecem, geralmente, preservando mais um caráter quantitativo, pois avaliar qualitativamente ainda é considerado "trabalhoso", pelo fato de ter que dispensar esforços relacionados ao tempo e à atenção a parâmetros mais particulares e subjetivos que envolvem as ações sociais.

A avaliação das ações de extensão se constitui em uma das diretrizes da Política de Extensão Unochapecó que se constituiu como campo de pesquisa-ação visando a elaboração do trabalho final do mestrado profissional cursado. Nessa perspectiva, avaliar os projetos sociais desenvolvidos por essa Universidade reafirma o compromisso ético-político na relação com a comunidade e a busca pela qualificação das ações prestadas aos seus usuários, ampliando os processos participativos e de controle social, em âmbito institucional e fora dele.

O reconhecimento inquestionável, manifestado pelos sujeitos participantes do da construção do trabalho final de mestrado, vem reforçar a importância da organização de um sistema de avaliação dos projetos sociais e, ao mesmo tempo, revelar as dificuldades que estão presentes no sentido de ampliar os níveis de participação e, em decorrência, obter maior densidade e efetividade ao processar ao debater e decidir coletivamente sobre o monitoramento e avaliação desses projetos considerando a lógica da abordagem participativa.

Avaliar de modo participativo, não se constitui numa tarefa fácil. Exige, pois, uma participação ampla e efetiva dos que estão envolvidos nos diferentes e complementares processos constitutivos do monitoramento e avaliação de projetos sociais, para consolidar compromissos coletivos ao acionar diferentes mecanismos e instrumentos para sua gestão. 


\section{REFERÊNCIAS}

ARMANI, Domingos. Como elaborar projetos sociais? guia prático para elaboração e gestão de projetos sociais. Porto Alegre: Tomo Editorial, 2009.

BRASIL. Plano Nacional de Extensão Universitária. Fórum de Pró-Reitores de Extensão das Universidades Públicas Brasileiras e Sesu/MEC, 2001.

Política Nacional da Assistência Social. Brasília: Ministério do Desenvolvimento Social e Combate à Fome, 2004. Disponível em: http://www.mds.gov.br/falemds/perguntasfrequentes/assistencia-social/assistencia-social/usuario/pnas-politica-nacional-de-assistenciasocial-institucional. Acesso em: 05 nov. 2010.

Portaria Normativa n. 17 de 28 de dezembro de 2009. Dispõe sobre o mestrado profissional no âmbito da Fundação Coordenação de Aperfeiçoamento de Pessoal de Nível Superior - CAPES. Brasília, 2009. Disponível em: $<$ http://portal.mec.gov.br/dmdocuments/port_mestrado_profissional1.pdf>. Acesso em: 06 jun. 2011.

CARVAlHO, Maria do Carmo Brant de. Avaliação de Projetos Sociais. In: ÁVILA, Célia M. de. (Coord.). Gestão de Projetos Sociais. 3. ed. São Paulo: AAPCS, 2001.

COHEN, Ernesto; FRANCO, Rolando. Avaliação de Projetos Sociais. 5. ed. Petrópolis: Vozes, 2002.

FERREIRA, Aurélio Buarque de Holanda. Miniaurélio Século XXI: o minidicionário da Língua Portuguesa. Rio de Janeiro: Nova Fronteira, 2000.

MINAYO, Maria Cecília de Souza; DESLANDES, Suely Ferreira. Caminhos do pensamento: epistemologia e método. Rio de Janeiro: Editora Fiocruz, 2002.

PEREIRA, Luiz Carlos Bresser. A Reforma do Estado dos anos 90: lógica e mecanismo de controle. Brasília: Ministério da Administração Federal e Reforma do Estado, 1997.

ROMERO, Sonia Mara. Psicologia e pesquisa. Porto Alegre: Sulina, 2008.

STEPHANOU, Luis et al. Guia para elaboração de projetos sociais. Porto Alegre: Fundação Luterana de Diaconia, 2003.

THIOLLENT, Michel. Metodologia da pesquisa-ação. 15. ed. São Paulo: Cortez, 2007.

UNOCHAPECÓ. Universidade Comunitária da Região de Chapecó Política de Extensão Universitária. Resolução n. 167/CONSUN/2010. Aprova a Alteração da Política de Extensão Universitária da Universidade Comunitária da Região de Chapecó - UNOCHAPECÓ, Chapecó, 2010. Disponível em:

<www.unochapeco.edu.br/static/data/portal/publicacoes/5195.pdf>. Acesso em 22 jun.2012.

Universidade Comunitária da Região de Chapecó Política de Extensão Universitária. Resolução n. 098/CONSUN/2005. Aprova a Proposta de Princípios e Diretrizes da Unochapecó para o Plano de Desenvolvimento Institucional - PDI da Universidade Comunitária da Região de Chapecó - UNOCHAPECÓ, Chapecó, 2005. Disponível em: $<$ www.unochapeco.edu.br/static/data/portal/publicacoes/93.pdf $>$. Acesso em 12 jun.2012. 